\title{
Communicating with people with intellectual disabilities: a guide for general psychiatrists
}

\author{
Liz Boardman, Jane Bernal \& Sheila Hollins
}

\begin{abstract}
SUMMARY
Good communication is central to psychiatric consultation. It informs assessment, diagnosis and treatment, and is an important part of empowering people to take more control of their own mental health. But active listening and personally tailored explanations may require additional skills and may need to be practised in the context of ethical and legal frameworks. In this article we consider the additional impairments that occur in people with intellectual disabilities who use psychiatric services and describe practical steps that can be taken by clinicians and service providers to overcome these impairments, to make reasonable adjustments and to ensure that patients obtain maximum benefit from services.

\section{DECLARATION OF INTEREST}

S.H. is Executive Chair of Beyond Words. J.B. is a co-author of books in the Books Beyond Words series.
\end{abstract}

People with intellectual disabilities constitute about $2 \%$ of the population (Bernal 1995; Smiley 2007). However, for social, psychological and biological reasons they are at increased risk of developing mental illness (Smiley 2007; Einfeld 2010). Intellectual disabilities are also associated with other neurodevelopmental disorders, particularly those on the autism spectrum. Intellectual disability is classified in ICD-10 as mild, moderate, severe and profound mental retardation (World Health Organization 2010: F70-79), and we refer to these degrees of disability in this article.

Some people with intellectual disabilities have always been seen in general psychiatric clinics, but the numbers are likely to increase with policies and guidance that encourage them to use mainstream services wherever appropriate (Department of Health 2001; Cole 2004). Furthermore, legislation in the UK (the Equality Act 2010 in England, Wales and Scotland, the Disability Discrimination Act 1995 in Northern Ireland) requires mental health services to make reasonable adjustments to ensure that people with intellectual disabilities can access the same levels of service as other citizens. For some people this will involve referral to a highly specialist service (if available), but the majority will attend general psychiatric clinics. The Mental Capacity Act 2005 introduced guidelines for independent advocacy and deprivation of liberty safeguards, and a simplified summary of the Act has been published for people with intellectual disabilities (Department for Constitutional Affairs 2007). The Adults with Incapacity (Scotland) Act 2000 requires clinicians to encourage the adult to exercise residual capacity.

\section{Health literacy}

People with intellectual disabilities usually have very limited health literacy, and health providers have a responsibility to find ways to help them make appropriate use of services (Michael 2008; Raynor 2012). Raynor \& Theo (2012) have suggested that there are three aspects to health literacy:

- the patient's ability to read and understand health information

- the patient's ability to engage with the healthcare process

- the removal by healthcare systems of unnecessary complexity and barriers to patients' understanding and involvement.

In terms of the first point on the list, it would be wrong to make assumptions about a person's ability to understand health information on the basis of their verbal skills, including their ability to read words. Information can also be 'read' in pictures or through experience. As regards the second point, an ability to engage with the healthcare process may require that the person is supported in a particular way by someone who is familiar with their communication needs. The final point is of critical importance, and responsibility for making reasonable adjustments, such as through the provision of visual material and other communication resources, should rest with each clinician, helped by their managers.

\section{ARTICLE}

Liz Boardman is a highly specialist speech and language therapist with Cornwall Partnership NHS Foundation Trust. Jane Bernal is a consultant in developmental neuropsychiatry, also with Cornwall Partnership NHS Foundation Trust. Sheila Hollins is Emeritus Professor of the Psychiatry of Disability at St George's, University of London and Executive Chair of Beyond Words, a notfor-profit social enterprise that published books and provides services for adults and teenagers with intellectual disabilities, their family carers, support workers and other professionals. Correspondence Professor Sheila Hollins, Division of Population Health Sciences and Education, St George's, University of London, Cranmer Terrace, London SW17 ORE, UK.Email: hollinss@parliament.uk 


\section{Communication skills}

Clinical communication can be seen as a two-way process or partnership, involving the exchange of information between clinician and patient, and developing a shared understanding that in turn leads to appropriate and effective intervention. It is the responsibility of both communication partners. Where one partner has impairments in understanding, processing or articulating ideas, the other partner, usually the clinician, has a greater responsibility to ensure that the process works.

Everyone communicates in some way, even when they are unable to use words and lack internal language. Most people with intellectual disabilities experience communication difficulties of some sort. Emerson et al (2001) suggested that $80 \%$ of people with severe intellectual disabilities would never develop effective speech. By contrast, people with mild intellectual disabilities often have superficially adequate speech and language skills, and it is only on further investigation that more subtle communication problems become apparent. These difficulties can be further complicated if the person is on the autism spectrum.

It is particularly easy to overestimate the comprehension of people with moderate intellectual disabilities and to misinterpret their behavioural challenges as being psychiatric in nature. There is a tendency to prioritise speech as the main form of communication, even when there is evidence that the individual has limited understanding of the spoken word. It is easy to forget to take into account the importance of contextual cues in aiding understanding. A person who complies with the instruction 'Come and have your lunch' may be able to do so without understanding any verbal language, if they have seen the table being laid and their lunch dished up (Bradshaw 2001).

The communication skills of people with intellectual disabilities can be divided into three broad developmental categories: pre-symbolic, symbolic and verbal. In focusing on symbolic and verbal communication, the reader might conclude that symbolic language, whether expressed in speech or sign, is at the core of the clinical encounter. However, meaningful and therapeutic encounters also occur in the communication of affect and the affective resonance of the clinician to the patient's non-verbal signals. Some would argue that much of what goes on in the human encounter is nonverbal and non-symbolic.

\section{Pre-symbolic communication}

People who only use pre-symbolic communication (likely to be those with very severe or profound intellectual disabilities) will be unable to understand or use symbolic forms of communication such as speech, pictures, photographs or signs. They will largely rely on the people around them to anticipate their needs and to interpret their vocalisations, facial expressions and body language (Coupe O'Kane 1998). They are unlikely to present to general adult psychiatrists in the UK, although they may in parts of the world where there are no specialist psychiatrists working with people with intellectual disabilities. Wherever they present, they should always be seen with a familiar person who knows their idiosyncratic communication style. There are strategies clinicians can use to optimise their therapeutic engagement which are applicable across all communication capacities. These strategies will be discussed further below under 'Specific impairments'.

\section{Symbolic communication}

About $60 \%$ of people with intellectual disabilities are able to use symbolic methods such as pictures, symbols, signs or speech to communicate (Emerson 2001). This is despite the much higher prevalence of additional sensory impairments that may add another communication barrier (Box 1). Some people may only understand very basic everyday phrases, and perhaps recognise a few familiar photographs, whereas others may have a much greater understanding of language and be able to recognise a variety of different pictures and/or symbols. They may be able to respond to a pictorial narrative even when they do not use words. For example, one of our patients with Down syndrome who was non-verbal was able to follow the Books Beyond Words picture book When Dad Died (Hollins 2004), turning the pages himself, pausing longer on pictures that seemed to remind him of his own father's death, crying and smiling appropriately as the story progressed (Fig. 1).

BOX 1 Sensory impairment and communication

- 50-60\% of people with intellectual disabilities have a hearing impairment (Emerson 2001):

- hearing problems are frequently unreported by people with intellectual disabilities and their carers

- hearing problems may lead to increased communication difficulties as well as social and psychological difficulties (Arlinger 2003)

- About $40 \%$ of people with intellectual disabilities will have problems with their sight (Emerson 2001) 


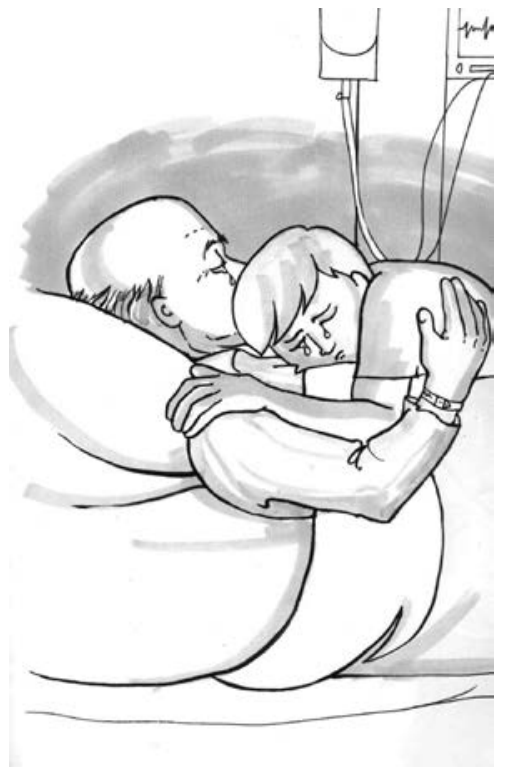

Image from When Dad Died (Hollins 2004). (C) Sheila Hollins and Beth Webb.

\section{Verbal communication}

Most people with intellectual disabilities have mild disabilities and, although they will vary in their ability to understand spoken, pictorial or sign language and to express themselves, they will use speech or sign as their predominant form of communication (Barron 2009). It is still important to check for shared understanding, for example of time and consequences. Tuffrey-Wijne (2012) quotes a parent, talking about her son:

'My son's understanding is very concrete. He takes things literally. My sister was dying of cancer, and every time I visited her, I'd come home and he would ask, "is she dead yet?" We had told him that she was going to die, so he asks, "why isn't she dead yet? You told me she was going to die!" So if you told him he was going to die, he would ask: "When? What day? What time?" You can't tell him something is going to happen, and then not tell him when.'

\section{Pragmatics}

Pragmatics has been defined as "how we use our communication skills with various people and in different situations. It involves the way communication is used to dictate how, when and with whom to talk, and for what purpose' (Elliott 2001: p. 241). Pragmatics covers such areas as: initiation; topic selection, maintenance and closure; turn-taking; repairing conversational breakdown; and use of appropriate conversational style. This area of communication is particularly problematic for people with autism spectrum disorders (Shields 2001). However, people who have mild intellectual disabilities but not autism may also experience difficulties with social interaction (Kernan 1997).

\section{Specific impairments}

\section{Autism}

People with autism present with a typical triad of impairments that relate to social interaction, social communication and imagination. Language development and the use of functional language can vary greatly: some individuals with autism and severe intellectual disabilities never develop language (Shields 2001), whereas those with high-functioning autism (autism associated with an IQ outside the intellectual disabilities range) may exhibit pragmatic and higher-level language difficulties.

Social communication issues observed in autism spectrum disorders include: difficulties understanding and showing empathy and emotion; obsessively talking about topics that are motivating to themselves, but showing little interest in nonpreferred topics; difficulty making inferences (Paul 2009). Conversation with a person with autism often goes well as long as it is on a subject that the person chooses. When the clinician needs to direct the conversation, things become more difficult and the person's conversation may seem one-sided and egocentric.

People with autism tend to take language literally and find it difficult to comprehend metaphors, irony and humour (Shields 2001). For example, a mental health service creates a 'Rainy Day Plan' to empower service users to say in advance what should happen if they become ill again. This can confuse those with autism, who may ask why the plan is only valid in wet weather.

Everyday language - 'going off the rails', 'losing your rag', 'seeing red', even 'feeling blue' - may be as confusing as medical jargon to a person with autism. Even those who use metaphors in their own speech may find it difficult to understand when other people do so. People with autism may have excellent reading and auditory memory skills and can unintentionally mislead the clinician into thinking full understanding has been achieved.

\section{Vignette 1}

A young man with autism in our clinic who was capable of reading the British National Formulary (BNF) said, 'I don't want to start those tablets, they cause nausea'. 'What is nausea?', the psychiatrist asked. 'When you are nauseated', the young man replied. 'What does being nauseated feel like?' - 'I have no idea. But it must be something very bad.' 


\section{Cerebral palsy}

Cerebral palsy is a non-progressive motor impairment which may be associated with intellectual disabilities. However, intellectual impairment should not be assumed in those unable to speak clearly or at all. The dysarthria associated with cerebral palsy often results in severe speech intelligibility problems (Gerenser 2007) and some individuals have no recognisable speech. Cerebral palsy is included here as a reminder that comorbid intellectual disability should not be assumed simply because a person's expressive language is impaired.

\section{Profound and multiple impairments}

People in this group may have pre-symbolic communication skills, and the quality of the clinical encounter will rely heavily on the clinician's capacity to be sensitive to each individual's way of engaging. Intensive interaction (Nind 1996; Caldwell 2011, 2012), which is used in the UK, and integrated therapy for attachment and behaviour, which has been spearheaded in The Netherlands (Sterkenburg 2008) are both strategies which focus on the person's affect.

\section{Interacting with people with intellectual disabilities: problems and solutions}

\section{Common communication problems}

People with intellectual disabilities are more likely to be acquiescent and to yield to leading questions (Clare 1993). Closed questions requiring yes/no answers are therefore particularly problematic: individuals may appear to answer correctly when in fact they have not understood and have merely used their knowledge of question structure and non-verbal cues (such as tone of voice and facial expression) to give the response they think the listener is expecting (Elliott 2001). Open questions (e.g. 'What do you like doing on holiday?') can also be difficult, as they require the person to think of and then retain a number of possible answers, while simultaneously having to structure their response in a coherent way. The high prevalence of hearing and visual impairments presents additional communication difficulties (Emerson 2001). The clinician should also enquire about these.

\section{Solutions}

Questions or information should be broken down into small chunks, and the clinician should keep checking that the person understands before moving on (Tuffrey-Wijne 2012).

Presenting questions in an either/or format ('Do you like sailing or reading?') is often easier for the patient than using open questions, but care must be taken to ensure that the person is not simply repeating the final option given (Barron 2009). People with intellectual disabilities may feign understanding and voice opinions or comments that they have 'borrowed' from others (Kernan 1997). It is therefore important to check the individual's own understanding of the words and phrases they use, and not assume that their understanding of particular words is the same as the clinician's.

\section{Communication skills for the clinician}

When working with people with limited understanding of language it is essential to use short, simple sentences with everyday words, to avoid jargon and to allow time for the individual to process information. Careful attention to body language, and showing respect, warmth and patience, are even more important than with other groups of patients. Clinicians should be ready to use pictures and photographs, as well as facial expression, affect and tone of voice, to show that they have understood what the patient says (Barron 2009; Caldwell 2012). It is essential that people with intellectual disabilities are given time to formulate a response. They may process language more slowly, and once they have understood a question, they may be slower to think through their answer. Rephrasing the question, a common strategy for clinicians, will add to the information overload if the person is still processing the original one. Clearly, there are important training implications for all clinical disciplines.

\section{Conducting a psychiatric assessment}

Conducting a psychiatric assessment of a patient with an intellectual disability requires a different approach from that used with other patients.

\section{Preparation in advance}

If at all possible, find out before the interview how the patient prefers to communicate. The use of an informant-rated interview schedule such as the Mini PAS-ADD (Prosser 1998) ahead of the interview frees up time for questions on the day. It is also useful to know before you meet them whether the patient has any hypersensitivities, such as to noise, or any strategies that help them regulate their behaviour.

It is usually advisable to allow a longer appointment time and to check who will be accompanying the patient to the appointment.

Have a notebook and pens handy, and plan to record your clinical notes on the computer later. Pictures, 'easy read' leaflets and picture books such as Books Beyond Words (Hollins 2010) can 
all be helpful in the clinical encounter. These are discussed further in the section 'Resources to support communication'.

\section{Introductions}

Introductions are important. Clinicians normally begin by introducing themselves to the patient with a welcoming handshake and making eye contact. The way the patient responds to this is the beginning of an assessment of their confidence, communication skills and mental state. However, these usual social overtures may not be experienced as intended by people with intellectual disabilities, particularly those with autism spectrum disorders. The clinician must be constantly observant of individual behavioural responses, as these behaviours, however apparently bizarre, may be demonstrating the way in which the patient finds it most acceptable to communicate. So one task for the clinician is to step outside their own frame of reference and learn about the frame of reference of the patient, by considering the adaptive function of any unusual behaviours. So, for example, a patient with autism who avoids eye contact may be more settled in the meeting if the clinician also avoids direct eye contact.

\section{Vignette 2}

A middle-aged and quite verbal woman who had been described as having a moderate intellectual disability was brought into the side room of a hospital ward to meet me (S.H.) for an assessment. She responded to my words of welcome by turning and looking out of the window on the other side of the room. She did not make eye contact with me and as far as I could see did not look at me at all. In return, I also turned to one side and waited for her to start the 'conversation', which soon became a string of questions about me. I was surprised when she commented that I had blue eyes like her. After her assessment of me, I was able to ask her some questions too.

\section{Working with supporters}

People with intellectual disabilities often attend the clinic with someone. That person may be there only to support and facilitate the patient's communication, or they may be a paid carer, family member or advocate with their own information to share and questions to ask (in what is sometimes called a triadic consultation). It is important to establish the role of the accompanying person early in the interview, how long they have known the patient, as they may be new, and to ask the patient if they want the person to stay. Sometimes their presence reduces anxiety and makes for a better interview, but adults with intellectual disabilities have the same right to ask for privacy as any other patient. If the wrong supporter has come, it may be necessary to arrange an early follow-up and to specify the support required for a successful consultation.

It is good practice to talk first to the patient, unless they indicate they do not want this. It can help to agree a structure for the interview: 'Is it OK if I talk with you for a few minutes? Then can I talk to X? Then perhaps we should all work out what to do next.' The accompanying person may well hold important information, for example about risk, sleep patterns or idiosyncratic use of language, that the patient may not know or realise is important.

\section{Mental state examination}

Assessment of the patient's understanding and their use of spoken and body language forms an important part of the mental state examination. It is helpful to know whether communication behaviour and use of language have recently changed. This will help to avoid diagnostic overshadowing - wrongly attributing all observed phenomena to the patient's intellectual disabilities (Reiss 1982). It is also important to avoid misdiagnosing psychosis on the basis of disorganised speech patterns that form part of a developmental language disorder. Recording a sample of the patient's actual speech, and of the interchange between clinician and patient, allows more effective support and consultation with professionals who were not present at the initial assessment.

\section{Assessment of capacity}

Assessment of capacity to consent to treatment involves giving information in the form the patient is most likely to understand and at the time they are most likely to understand it. This will be different for different patients. It is then necessary to check that the patient has understood the information provided and is able to weigh it up to make an informed decision. The emphasis is on giving information to the patient, not just to their supporter.

Assessment of capacity is a two-way process based on the ethical principle of autonomy, which guides the clinician in the way they relate to the patient. Even where a patient lacks capacity, it is essential to understand and record their views and to use this in discussions about their best interests (as required by capacity legislation). In some situations, it is the authority of the psychiatrist as an advocate to secure essential support from Social Services that is the most important outcome of the consultation. 


\section{Talking treatments}

Psychological therapies can be very helpful for people with intellectual and communication difficulties, although techniques will need to be adjusted to take account of the person's specific needs. For example, an assessment for therapy may take longer than one or two sessions, during which time the patient's experience of being in therapy may actually be more useful for both patient and therapist than a more abstract discussion of what therapy can offer. Therapy is likely to involve more sessions and may require the use of different media, such as pictures, photographs, drawing or even puppets. Both individual and group therapies have been found successful, and supportive therapy with and without the carer being present can be an effective way of identifying environmental factors that might be exacerbating mental and behavioural symptoms (Hollins 2000; Parkes 2004).

\section{General resources to support communication}

Many resources are widely available to help clinicians understand and communicate with people who have intellectual disabilities. Some of these are outlined in Box 2 or considered in more detail below.

\section{Passports}

Individuals with intellectual disabilities increasingly have 'passports' intended to help them in

BOX 2 Suggested resources

Understanding intellectual disability and health (www.intellectualdisability.info)

A website for healthcare students and professionals published by St George's, University of London and the University of Hertfordshire

Books Beyond Words (www. booksbeyondwords.co.uk)

Publishes picture books in print and as e-books, in English and other languages, and offers DVDs and training workshops on how to use picture stories to improve communication. A PowerPoint presentation on how to use Books Beyond Words in clinical settings is available at: www. booksbeyondwords.co.uk/node/149

The Green Light toolkit (Cole 2004) A framework and self-audit toolkit for improving services for people with intellectual disabilities who also have mental health problems

Talking Mats ${ }^{\circledR}$ (www.talkingmats.com)

A well-researched communication framework that enables people who have difficulty communicating to express their views (Bell 2008)

\section{Hospital passports}

Many areas now publish their own version: for examples see under $\mathrm{H}$ at www.easyhealth.org.uk

Easy read public information

Easy read information about medication and common mental disorders is available to download from the Royal College of Psychiatrists website: www.rcpsych.ac.uk/ expertadvice/problems/learningdisabilities. aspx their interactions with health and social care services. 'Hospital passports' (Box 2) are now widely used to enable patients with intellectual disabilities to carry with them a summary of their medical information and support needs to inform medical and nursing staff in the event of a hospital admission (Blair 2010). The psychiatrist should update the individual's passport for any psychiatric treatment given. 'Personal communication passports', first developed for use with children with complex communication difficulties (Millar 2009), contain more general information about the individual. This might include the way they communicate, their hearing or visual difficulties, likes and dislikes, family and friends, and dietary needs.

\section{'Easy read' information}

The 'easy read' format was developed to provide printed (or online) information for people who do not read well. It uses simplified text (with explanations of any technical terms or abbreviations), a clear font and illustrations or photographs to support understanding. Key points and important issues are highlighted and explained as simply as possible (Department of Health 2010).

'Easy read' documents on a range of health topics are increasingly available free online. For example, easy read information on mental health problems, specific treatments and common medications can be downloaded from the Royal College of Psychiatrists website (Box 2).

Clinicians can produce their own easy read material, although just adding a few pictures to a document does not automatically make it 'easy read'.

It is important to note that people with intellectual disabilities will still need help to read easy read documents unless they have good basic literacy (Department of Health 2010). This type of information can be useful even when working with people who cannot read, as it provides a simple and consistent script to follow when giving verbal explanations.

\section{Picture books and pictorial leaflets}

Many people process visual information more easily than auditory information, especially when they are feeling anxious in an unfamiliar clinical setting. Clinicians need to be ready to work with whatever visual material is available to support a person's communication and memory. This might include magazine pictures and their own drawings, but purpose-designed books, leaflets and internet resources are now readily available. 


\section{Beyond Words}

Books Beyond Words and Beyond Words leaflets (Box 2) are intended for people who cannot read. They use pictures to discuss health and social care issues in specially created scenarios and stories. Topics include health promotion, using health services and particular illnesses or experiences. Doctors and other clinicians can use Books Beyond Words after only a brief induction, which is available online (Hollins 2013), or face to face from an experienced user or in a workshop (Bradley 2013).

As well as supporting communication and memory, these pictorial stories go a step further in offering pictures that evoke emotional experience and expression. The clinician can use them to explore what a person already knows or feels about a situation or relationship, to check understanding, to give information, or more creatively as a basis for counselling and talking treatments.

For example, Ron's Feeling Blue (Hollins 2011) tells the story of a young man who becomes depressed, following him through treatment and recovery. He does not seem to enjoy his usual activities, goes off his food, and angrily pushes away the carer who offers him a drink (Fig. 2). 'He gets cranky, like me', observed one of our depressed patients.

When using picture stories without written words with a patient, clinicians should familiarise themselves with the story first. Books in the Books Beyond Words series include a suggested storyline and background information for carers and health professionals to refer to. There is an art to reading pictures and such preparation leads to a more relaxed clinical encounter. However, the skill when sharing a pictorial story with a patient is to withhold one's own interpretation and help the patient to share their own understanding, allowing them to slide into telling their own story if they want to, thus using the pictures as a projective tool.

\section{Talking Mats ${ }^{\circledR}$}

Talking Mats ${ }^{\circledast}$ is a method of engaging people that many clinicians find helpful and easy to use. They provide a way of discussing and recording an individual's views and opinions, and can be used to obtain information or facilitate decisionmaking. The approach has been used successfully with a range of people who have communication difficulties, including those with physical and intellectual disabilities (Bell 2008).

Pictures corresponding to a visual rating scale (e.g. like; don't mind; don't like) are placed along

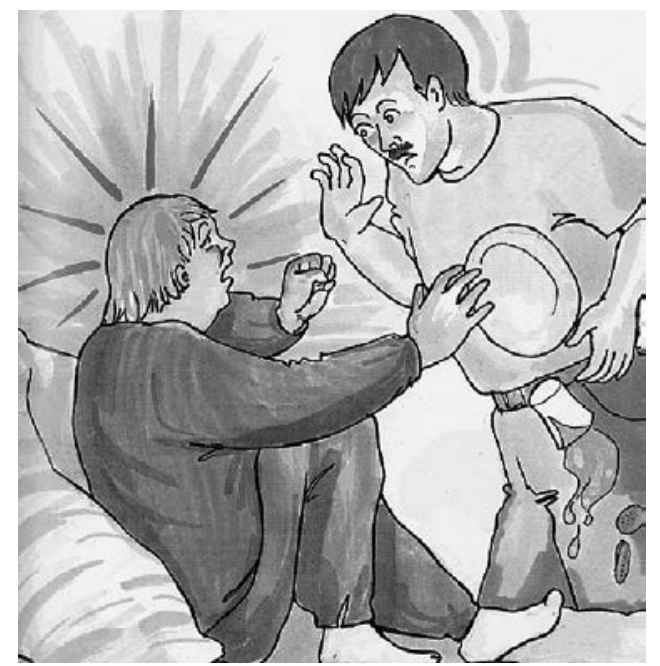

FIG 2

Image from Ron's Feeling Blue (Hollins 2011). (C) Sheila Hollins and Beth Webb.

the top of the 'mat'. A picture representing a particular topic (e.g. household tasks) is placed in the centre of the mat. The participant is then given a set of pictures that relate to the topic (e.g. cooking; dusting; vacuuming) and is asked to put the picture on the appropriate part of the visual rating scale. At the end of the exercise, the participant will have expressed their views on the particular topic, and 'sub-mats' can then be created to explore particular issues in further detail (e.g. why a participant dislikes cooking).

The use of Talking Mats ${ }^{\oplus}$ is an effective approach for those who understand at least three key words in a sentence (Murphy 2008), as well as for those who have good understanding and speech but are reluctant to express themselves verbally (Bell 2008).

\section{Symbols and visual schedules}

Symbols, pictures and photographs can be used in a variety of ways to support understanding and enable communication and choice-making. For example, a symbols board consisting of pictures of drinks and food enables a person to communicate (either by direction of gaze, fistpointing or finger-pointing) what they would like at mealtime. Visual schedules (also known as sequence strips) - a row of symbols on a Velcro ${ }^{\circledR}$ strip - are used to show the individual what is going to happen next. For example, a strip of four symbols might illustrate: breakfast; tidy room; go to see their doctor; have lunch. Visual schedules (e.g. getting up; mealtimes; activities; going to bed) are particularly helpful for people who do not understand concepts of time in their daily routine (Anderson 1997). 
B0X 3 Specialist methods to aid communication

\section{Signing}

Signing is a useful form of communication for those who are non-verbal or whose speech is very limited (Powell 1999).

Manual signing vocabularies such as Makaton ${ }^{\circledR}$ (Grove 1990) and Signalong (www.signalong.org.uk) consist of signs taken from British Sign Language. The signs are used alongside normal simplified speech to support understanding of verbal language and aid expression. Only the most important words or concepts in each sentence are signed.

The Picture Exchange Communication System (PECS)

Widely used with children with autism to teach communication using pictorial symbols (Charlop-Christy 2002), PECS is also used with children and adults with a range of developmental disabilities who have limited or no speech (Stoner 2006).

The system involves training the individual to exchange a picture of a motivating item or activity for the actual item or activity.

\section{Voice output communication aids (VOCAs)}

These are electronic communication devices which allow the user to convey a message using synthesised or recorded speech. Usually, communication software is loaded on to mainstream hardware such as laptops, although several companies still manufacture dedicated communication aids (ACE Centre 2010).

\section{Intensive interaction}

This is an approach to interacting with people with profound and multiple intellectual disabilities and/or autism (Caldwell 2011). The therapist engages emotionally by observing and responding to the person's unique body language, including their breathing, movements and sounds.

The approach builds on the familiar ways that parents communicate with pre-verbal infants. The aim is to bypass some of the processing difficulties associated with other attempts to communicate and to seek meaning in the person's behaviour.

\section{Integrated therapy for attachment and behaviour}

This evidence-based attachment therapy was developed in The Netherlands for people with intellectual disabilities with severe challenging behaviour and their caregivers (Sterkenburg 2008).

A 5-day training course is available in The Netherlands, and it includes learning to assess the quality of the caregiver/ client relationship and the use of video feedback to modify interactions.

\section{Objects of reference}

This approach is used with those who are at a pre-symbolic level of communication (Park 2003). It uses objects to help the individual predict what is going to happen next, and to make choices.

\section{Specialist resources}

Thetechniques most likely to be applied in specialist intellectual disabilities practice are best used with support from a speech and language therapist, psychotherapist or other trained professional. For example, if an individual uses sign as their first language, psychiatric consultation should involve a sign interpreter. A range of specialist resources and methods, including intensive interaction and integrated therapy for attachment and behaviour, are described briefly in Box 3 .

\section{Conclusions}

Clinicians need to develop their skills and knowledge in order to better support the health literacy and communication needs of patients with intellectual disabilities. They could do this by familiarising themselves with available communication methods, most of which do not need intensive training, and by understanding the range of different communication needs. In preparing well for consultations, they could ensure that appropriate resources are available. However, just as important is an attitude that places the needs of the patient at the centre of the consultation and accepts that there is an ethical responsibility to adapt an assessment and any interventions to take account of each patient's needs and impairments. In the UK, this extends to a legal requirement to make reasonable adjustments to all services to ensure equality of access.

It is very rewarding to gain the trust and confidence of a patient with an intellectual disability, and the communication skills described in this article may be transferable to clinical work with other patients, such as those with thought disorder or dementia.

\section{References}

ACE Centre (2010) What is a communication aid? ACE Centre.

Anderson MD, Sherman JA, Sheldon JB, et al (1997) Picture activity schedules and engagement of adults with mental retardation in a group home. Research in Developmental Disabilities, 18: 231-50.

Arlinger S (2003) Negative consequences of uncorrected hearing loss: a review. International Journal of Audiology, 42 (suppl 2): S17-20.

Barron D, Winn E (2009) Effective communication. In Intellectual Disability Psychiatry: A Practical Handbook (eds A Hassiotis, DA Barron, ( Hall): 3-19. John Wiley \& Sons.

Bell DM, Cameron L (2008) From Dare I say ... ? to I dare say: a case example illustrating the extension of the use of Talking Mats to people with learning disabilities who are able to speak well but unwilling to do so. British Journal of Learning Disabilities, 36: 122-7. 
Bernal J, Hollins S (1995) Psychiatric illness and learning disability: a dual diagnosis. Advances in Psychiatric Treatment, 1: 138-45.

Blair J, Glaysher K, Cooper S (2010) Passport to health. Learning Disability Today Jan: 28-30 (available at http://www.intellectualdisability.info/ how-to../). Accessed 21 Aug 2013.

Bradley E, Hollins S (2013) Books Beyond Words: Using Pictures to Communicate. Journal of Developmental Disabilities, 19: 24-32.

Bradshaw J (2001) Complexity of staff communication and reported level of understanding skills in adults with intellectual disability. Journal of Intellectual Disability Research, 45: 233-43.

Caldwell P (2011) Intensive interaction: using body language to communicate. St George's, University of London (available at http:// www.intellectualdisability.info/how-to../). Accessed 21 Aug 2013.

Caldwell P (2012) Listening with All Our Senses. Pavilion.

Charlop-Christy MH, Carpenter M, Loc L, et al (2002) Using the Picture Exchange Communication System (PECS) with children with autism: assessment of PECS acquisition, speech, social-communicative behavior and problem behavior. Journal of Applied Behavior Analysis, 35: 213-31.

Clare CH, Gudjonsson GH (1993) Interrogative suggestibility, confabulation, and acquiescence in people with mild learning disabilities (mental handicap): implications for reliability during police interrogations. British Journal of Clinical Psychology, 32: 295-301.

Cole A, Gregory M (2004) Green Light for Mental Health: A Service Improvement Toolkit. Foundation for People with Learning Disabilities.

Coupe O'Kane J, Goldbart J (1998) Communication before Speech. David Fulton Publishers.

Department for Constitutional Affairs, Department of Health, Welsh Assembly Government (2007) The Mental Capacity Act: Easy Read Summary. Department for Constitutional Affairs (http://www.dca.gov. uk/menincap/mca-act-easyread.pdf). Accessed 21 Aug 2013.

Department of Health (2001) Valuing People: A New Strategy for Learning Disability for the 21st Century. Department of Health.

Department of Health (2010) Making Written Information Easier to Understand for People with Learning Disabilities: Guidance for People who Commission or Produce Easy Read Information - Revised Edition 2010. Department of Health.

Einfeld SL, Ellis L, Doran CM, et al (2010) Behaviour problems increase costs of care of children with intellectual disabilities. Journal of Mental Health Research in Intellectual Disabilities, 3: 202-9.

Elliott K, Forshaw N (2001) People with borderline-mild learning disability. In Communication and Mental IIIness: Theoretical and Practical Approaches (eds J France, S Kramer): 236-50. Jessica Kingsley Publishers.

Emerson E, Hatton C, Felce D (2001) Learning Disabilities: The Fundamental Facts. Foundation for People with Learning Disabilities.

Gerenser J, Forman B (2007) Speech and language deficits in children with developmental disabilities. In Handbook of Intellectual and Developmental Disabilities (eds JW Jacobson, JA Mulick, J Rojahn): 563-79. Springer.

Grove N, Walker M (1990) The Makaton Vocabulary: using manual signs and graphic symbols to develop interpersonal communication. Augmentative and Alternative Communication, 6: 15-28.

Hollins S, Sinason V (2000) Psychotherapy, learning disabilities and trauma: new perspectives. British Journal of Psychiatry, 176: 32-6.

Hollins S, Sireling L (2004) When Dad Died (3rd edn). Books Beyond Words.

Hollins S (2010) Books Beyond Words: telling the whole story in pictures. (available at http://www.intellectualdisability.info/how-to../). Accessed 21 Aug 2013

Hollins S, Banks R, Curran J (2011) Ron's Feeling Blue (2nd edn). Books Beyond Words.
Hollins S (2013) Using Books Beyond Words in Therapy and in the Clinic. Beyond Words.

Kernan KT, Sabsay S (1997) Communication in social interactions: aspects of an ethnography of communication of mildly mentally handicapped adults. In Language and Communication in People with Learning Disabilities (revised edn) (eds M Beveridge, G Conti-Ramsden, I Leudar): 229-53. Routledge.

Michael J (2008) Healthcare for All: Report of the Independent Inquiry into Access to Healthcare for People with Learning Disabilities. Department of Health.

Millar S, Aitken S (2009) Personal Communication Passports as a Way of Consulting and Representing Children with Communication Disabilities, to Ensure Consistent Care. Communication Aids for Language and Learning (CALL) Centre, University of Edinburgh (http:// www.communicationpassports.org.uk/Common-Assets/spaw2/uploads/ files/intropassports.pdf). Accessed 21 Aug 2013.

Murphy J, Cameron L (2008) The effectiveness of Talking Mats ${ }^{\circledR}$ with people with intellectual disability. British Journal of Learning Disabilities 36: 232-41.

Nind M (1996) Efficacy of intensive interaction: developing sociability and communication in people with severe and complex learning difficulties using an approach based on the caregiver-infant interaction. European Journal of Special Educational Needs 11: 48-66.

Park K (2003) A voice and a choice. Special Children Magazine 153: Feb/ Mar.

Parkes G, Mukherjee R, Karagianni E, et al (2004) Characteristics and outcomes of referrals to a psychotherapy service for people with intellectual disabilities (ID) (Proceedings of the IASSID World Congress, 2004 (abstract)). Journal of Intellectual Disability Research 48: 311.

Paul R, Hare KP (2009) Assessing speech, language and communication in autism spectrum disorders. In Assessment of Autism Spectrum Disorders (eds S Goldstein, JA Nagleri, S Ozonoff): 171-208. Guilford Press.

Powell G (1999) Current research findings to support the use of signs with adults and children who have intellectual and communication difficulties (available at http://www.makaton.org/Assets/researchPapers/ powell1999.pdf). Accessed 21 Aug 2013.

Prosser H, Moss S, Costello H, et al (1998) Reliability and validity of the Mini PAS-ADD for assessing psychiatric disorders in adults with intellectual disability. Journal of Intellectual Disability Research 42 : 264-72.

Raynor D, Theo K (2012) Health literacy: is it time to shift our focus from patient to provider? BMJ 344: e2188.

Reiss S, Lewitan DW, Szysko J (1982) Emotional disturbance and mental retardation: diagnostic overshadowing. American Journal of Mental Deficiency 86: 567-74

Shields J, Hare D (2001) Communication and mental health in people with autism and Asperger's syndrome. In Communication and Mental IIIness (eds J France, S Kramer): 262-6. Jessica Kingsley Publishers.

Smiley E, Cooper SA, Finlayson J, et al (2007) Incidence and predictors of mental ill-health in adults with intellectual disabilities: prospective study. British Journal of Psychiatry 191: 313-9.

Sterkenburg P, Schuengel C, Janssen C (2008) Developing a therapeutic relationship with a blind client with a severe intellectual disability and persistent challenging behaviour. Disability and Rehabilitation 30: 1318-27.

Stoner JB, Beck AR, Bock SJ, et al (2006) The effectiveness of the picture exchange communication system with nonspeaking adults. Remedial and Special Education 27: 154-65

Tuffrey-Wijne I (2012) How to Break Bad News to People with Intellectual Disabilities: A Guide for Carers and Professionals. Jessica Kingsley Publishers.

World Health Organization (2010) International Statistical Classification of Diseases and Related Health Problems 10th Revision (ICD-10) Version for 2010 . WHO.
MCO answers

$1 \mathrm{~b} \quad 2 \mathrm{c} \quad 3 \mathrm{~d} \quad 4 \mathrm{a} \quad 5 \mathrm{c}$ 


\section{MCOs}

Select the single best option for each question stem

1 When patients with intellectual disabilities are referred to a general psychiatric clinic:

a the referral should always be passed on to the community learning disability team

b reasonable adjustments should be made to normal assessment and treatment to make it easier for the person to access the service

c a carer/support worker can speak on behalf of the patient

$d$ it is usually better for them to see a nurse instead of a psychiatrist

e support workers accompanying patients to the clinic will always know the person's background.

2 In communication with patients with intellectual disabilities:

a the clinician should just speak normally as they would to any patient b if the patient does not understand immediately, then they will not understand

c the clinician should show respect and warmth in their facial expression and voice

$\mathrm{d}$ if the patient does not understand a question straightaway, repeat it more loudly

e closed questions are better than open questions.

3 As regards developmental level of communication:

a most people with intellectual disabilities communicate only at the pre-symbolic level

b people with pre-symbolic communication skills are often referred to the general psychiatrist

c few people with intellectual disabilities are able to use symbolic methods to communicate

d pictures, symbols and signs are often an effective way of supporting someone's understanding of language

$\mathrm{e}$ it is safe to assume that someone who cannot speak cannot understand.
4 As regards pragmatic language use:

a it is the ability to conduct an effective conversation with another person

b people with high-functioning autism very seldom have pragmatic language problems

c someone with a pragmatic language disability can easily understand a 'rainy day plan'

d difficulties with social interaction are unique to people with autism

e someone with cerebral palsy who is dysarthric probably has pragmatic language difficulties.

5 Psychiatrists need professional training before they can use:

a Talking Mats ${ }^{\circledR}$

b Books Beyond Words picture books

c sign language

d hospital passports

e easy read leaflets. 